\title{
História da historiografia e memória disciplinar: reflexões sobre um gênero*
}

\section{History of historiography and disciplinary memory: reflections on a genre}

\author{
Rodrigo Turin \\ rodrigoturin@gmail.com \\ Professor adjunto \\ Universidade Federal do Estado do Rio de Janeiro \\ Escola de História \\ Av. Pasteur, 458 - Urca \\ 22290-240 - Rio de Janeiro - RJ \\ Brasil
}

\section{Resumo}

A partir das proposições de Peter Szondi a respeito de uma "poética histórica dos gêneros", este ensaio tem por objetivo interrogar os usos e os sentidos que configuram a história da historiografia como gênero de escrita da história. A partir dessa interrogação da história da historiografia em função de suas características enquanto gênero, procuro apontar para certos constrangimentos sedimentados historicamente em sua forma e que incidem diretamente nas possibilidades e nos limites de sua (re)definição como um campo de pesquisas e de reflexão.

\section{Palavras-chave}

História da historiografia; Manoel Salgado Guimarães; Gênero.

\begin{abstract}
The aim of this paper is to cross-examine, in light of Peter Szondi's "historical poetics of genres", the uses and meanings that configure history of historiography as a genre of historical writing. By doing so, this paper points out some constraints that were historically settled within the genre's form and that exert direct influence on the possibilities and restrictions for re(defining) the history of historiography as a research field.
\end{abstract}

\section{Keywords}

History of historiography; Manoel Salgado Guimarães; Gender.

Recebido em: 14/7/2013

Aprovado em: 18/9/2013

* Este ensaio contou com o apoio do CNPq. 
Desde a década de 1980, é possível perceber um crescimento significativo no número de publicações sobre a história da historiografia, que se expressou na instituição de linhas de pesquisa de pós-graduação, na organização de eventos especializados, assim como na criação de revistas dedicadas exclusivamente a promover e divulgar esse gênero de reflexão e produção historiográfica. Diante desse pujante crescimento, em um propalado contexto de crise epistemológica e do papel social da disciplina histórica (NOIRIEL 2005; HARTOG 2013), faz-se necessário interrogar quais são as expectativas e os constrangimentos que demarcam a atual inserção e a expansão da história da historiografia. Em que medida é possível identificar para ela uma identidade que a legitime e lhe dê estabilidade como um campo autônomo ou, mesmo, como um subcampo de pesquisas? É possível delimitar essa especificidade através da unidade de seu objeto, de sua metodologia, dos problemas em torno dos quais se desenvolve? Deve a história da historiografia exercer, ou exerce, algum tipo de função normativa diante da disciplina histórica como um todo? Estas são apenas algumas das questões que se colocam diante da comunidade de pesquisadores que vem se constituindo em torno dessa forma de escrita e pesquisa.

Os trabalhos de Manoel Luiz Lima Salgado Guimarães representam, para essas questões, uma referência incontornável. Desde sua tese de doutorado, produzida na década de 1980, até seus últimos artigos e capítulos de livros, ele não apenas contribuiu como poucos para a enorme expansão de uma agenda de pesquisas e de refexões sobre a história da historiografia brasileira, como também submeteu-a a uma constante reflexão acerca de seus alcances e de seus limites epistemológicos. Não há como abordar o conjunto de sua obra sem atentar para essa dupla dimensão, na qual a pesquisa sobre as formas de representação do passado e, mais especificamente, sobre a disciplina histórica, caminhava paralelamente a um questionamento constante em relação aos constrangimentos e às possibilidades legadas por essa mesma tradição disciplinar na qual se inseria. ${ }^{1}$ Uma das noções recorrentes em seus trabalhos e que mais sintetiza essa postura é, justamente, a de "memória disciplinar". Presente em diferentes textos, esta noção visava introduzir uma dimensão crítica necessária a todo trabalho hermenêutico da história da historiografia. Ela implicava reconhecer, acima de tudo, que o próprio surgimento deste lugar de enunciação, a história da historiografia, estava estritamente vinculado a um trabalho de memória, submetendo o passado a uma narrativa de identidade disciplinar (GUIMARÃES 2005). Uma memória que, em seu ordenamento narrativo, ao mesmo tempo dá a ver e silencia, condicionando invariavelmente a percepção de seus herdeiros a respeito do passado. Como ele afirmou, por exemplo, em relação ao (não)lugar ocupado pelos antiquários:

\footnotetext{
${ }_{1}^{1}$ Como destacaram Temístocles Cezar e Paulo Knauss em sua apresentação à tese de Manoel Salgado: "As pesquisas de Manoel Luiz Salgado Guimarães marcam um momento em que os historiadores (inicialmente um pequeno grupo) dubruçam-se sobre a sua disciplina e passaram a estudar sua própria memória disciplinar e os motivos de seus esquecimentos" (GUIMARÃES 2012, p. 15). Para uma análise de certas questões e antinomias que orientavam a produção historiográfica à época em que Manoel Salgado produzia sua tese, conferir ARAUJO (2012).
} 
Prisioneiros desta mesma memória disciplinar, reafirmamos as demarcações e as rupturas que era necessário este procedimento disciplinar constituir para se afirmar como portador de um conhecimento legítimo sobre o passado, deixando de perceber não apenas certas continuidades, mas, sobretudo, o jogo de silenciamento e de escolhas a que se procedeu para que os antiquários fossem vistos como incapazes de conhecer verdadeiramente o passado (GUIMARÃES 2007, p. 15).

Esta postura crítica, deve-se ressaltar, não se caracteriza pela falsa expectativa de conquista de uma completa autonomia frente à tradição. Trata-se, antes, de reconhecer os efeitos dessa tradição e, simultaneamente, enfrentá-los. Não há a busca de um olhar puro, despido de suas heranças. Há, isso sim, o constante e difícil esforço de tornar-se herdeiro. O que disso resulta para o trabalho da história da historiografia, tal como o entendia Manoel Salgado, era a necessidade de traduzir o reconhecimento desses constrangimentos materializados em uma memória disciplinar em uma vigilância ao mesmo tempo epistemológica e ética. Ou seja, a necessidade de explicitar os pontos de vista, expressos em problemas e categorias, como condição para melhor controlá-los, seja em sua dimensão cognitiva, seja em sua dimensão ética.

Nesse sentido, é possível identificar no conjunto de sua obra um movimento no qual as pesquisas acerca da história da disciplina e das culturas históricas são acompanhadas por uma crescente problematização da forma através da qual aquelas pesquisas se realizavam e se expressavam. Se, em sua tese de doutorado, o problema centrava-se em reconstutir "a conexão entre a consolidação do Estado nacional e o início da historiografia" brasileira (GUIMARÃES 2011, p. 55), desvelando as funções legitimadoras da escrita da história e seus efeitos no desenvolvimento histórico nacional; em seus trabalhos posteriores, sem jamais abandonar a preocupação com a relação entre política e história, Manoel Salgado passa cada vez mais a complexificar os instrumentos de investigação sobre aqueles vínculos, assim como a fraturar a linearidade narrativa de sua representação. Essa preocupação manifestou-se tanto em uma maior problematização do objeto de pesquisa da história da historiografia - a escrita da história - , em sua historicidade e em suas relações com diferentes culturas históricas, como também no esforço de reinserir em suas análises a indeterminação dos diferentes futuros que orientavam aquelas experiências do passado. É o que se percebe, por exemplo, seja em suas reflexões sobre tradições silenciadas pela memória disciplinar, como a dos antiquários, seja na compreensão daquilo que ele denominou de "textos fundadores" como formas de "disputas pelo passado" e pela própria normatização de uma história disciplinar no Brasil oitocentista (GUIMARÃES 2000; 2007). De acordo com Manoel Salgado:

A historiografia como investigação sistemática acerca das condições de emergência dos diferentes discursos sobre o passado, pressupõe como condição primeira reconhecer a historicidade do próprio ato de escrita da História, reconhecendo-o como inscrito num tempo e lugar. Em seguida, é necessário reconhecer esta escrita como resultando de disputas entre memórias, de forma a compreendê-la como parte das lutas travadas nas sociedades para dar significado ao mundo. Uma escrita que se impõe 
tende a silenciar sobre o percurso que a levou à vitória, que aparece ao final como decorrência natural; perde-se desta forma sua ancoragem no mundo como parte do drama social humano, quando escolhas são efetuadas, que definem o passado que se deseja, ou que se necessita, como forma de inventar um futuro (GUIMARÃES 2003, p. 23-24).

Desse modo, o objeto de investigação não pode ser deduzido de forma a-histórica, a partir de sua suposta natureza ou autenticidade, mas definido no confronto controlado entre as categorias de análise e os textos investigados, identificando as formas e os usos, eles próprios históricos, que configuravam os diferentes suportes e suas texturas temporais. Os textos, nessa perspectiva, não são tratados como exemplos de uma filosofia da história qualquer, mas pensados a partir do reconhecimento de sua própria obscuridade que, como já ressaltava Schleiermacher, demanda e justifica todo o esforço hermenêutico. Como consequência dessa problematização do texto em sua historicidade, a investigação da história da historiografia acaba por se constituir como um espaço eminentemente aberto de investigação e reflexão, inserida "necessariamente numa teia em que o diálogo com outros campos da pesquisa histórica se faz necesário" (GUIMARÃES 2005, p. 32).

A partir desses questionamentos presentes na obra de Manoel Salgado a respeito da relação entre história da historiografia e memória disciplinar, aqui apenas esboçados, o que procuro neste ensaio é propor uma ferramenta analítica que permita sistematizar essa relação a partir da interrogação de certos aspectos que demarcaram a formação da história da historiografia como um gênero específico e reconhecido de escrita histórica. $O$ que me interessa aqui é a relação entre forma e historicidade, ou, melhor dizendo, pensar a historicidade através da forma. A partir dessa interrogação da história da historiografia em função de suas características enquanto gênero de escrita, procuro apontar para certos constrangimentos sedimentados historicamente em sua forma e que incidem diretamente nas possibilidades e nos limites de sua (re)definição como um campo de pesquisas e de reflexão.

\section{A historicidade do gênero}

A proposta de uma abordagem a partir do gênero, aqui sugerida, faz uso dos encaminhamentos hermenêuticos que Peter Szondi elaborou acerca de uma "poética histórica dos gêneros" (SZONDI 2011; 2004). ${ }^{2}$ Para Szondi, não é possível pensar os gêneros como formas autosuficientes que demandam determinados tipos fixos de conteúdos (como o dramático, o épico, o lírico). A descrição aristotélica dos gêneros e suas distintas recepções normativas entre os séculos XV e XVIII estabeleceram relações estáveis e universais entre as diferentes formas e seus conteúdos. Diferentemente dessa definição aristotélica dualista, presente também em teóricos como Emil Steiger, Szondi retira da estética hegeliana e do diálogo com as reflexões de Lukács, Benjamin e Adorno a necessidade de pensar, ao mesmo tempo, a relação de identidade e a historicidade

\footnotetext{
${ }^{2}$ Sobre Szondi, conferir os dossiês em Boundary (1983), Telos (2007).
} 
de forma e conteúdo. Essa poética histórica, e não mais normativa, requer a tematização da forma como "conteúdo sedimentado", resultado da relação entre dois enunciados: "enunciados de conteúdo" e "enunciados formais". ${ }^{3}$ É a isto que Szondi define como uma "semântica das formas", cuja historicidade se daria na tensão interna provocada entre os constrangimentos sedimentados nos conteúdos das formas, ou seja, nos enunciados formais, e os novos conteúdos provenientes da experiência. Cito Szondi:

Com isso, porém já está dada a possibilidade de ambos entrarem em contradição. Se no caso da correspondência entre forma e conteúdo, a temática do último se desenvolve como que no quadro do enunciado formal, como um conjunto de problemas situado no interior de algo não problemático, a contradição surge quando o enunciado fixo e não questionado da forma passa a ser posto em questão pelo conteúdo (SZONDI 2011, p. 20).

É esta antinomia, continua Szondi, que torna problemática uma forma literária, como é o caso da crise do drama moderno por ele analisado. Seu foco é a contradição crescente que é possível perceber desde Ibsen entre o enunciado da forma do drama, enquanto modelo não problemático, e os novos conteúdos da sociedade burguesa tematizados pela dramaturgia. A incorporação pelo drama de elementos épicos, resultado de uma oposisão entre sujeito e objeto, acaba por relativizar a forma dramática, na medida em que insere nela seja a dimensão do passado como plano de inteligibilidade dos personagens (Ibsen), a perspectiva subjetiva pela qual a dimensão inter-humana é tematizada (Strindberg), ou a apresentação das condições objetivas, sociais, dos acontecimentos (Hauptmann). Essa tensão entre o gênero e os novos conteúdos levou da crise do drama às tentativas de sua superação, encaminhadas pela própria problematização de seus constrangimentos formais sedimentados. ${ }^{4} \mathrm{~A}$ historicidade, portanto, resulta aqui de um processo dinâmico, na qual "a ideia da obra só se revela em seu movimento para fora, em sua saída à diferença temporal" (SZONDI 2006, p. 167).

Essa abordagem da historicidade do gênero, como ressalta Szondi, não pode abstrair-se da materialidade dos textos analisados, reduzindo-os a alguma modalidade de "espírito de época" ou a algum "princípio constitutivo universal", pois é somente a partir das próprias obras, em seu caráter idiomático, que é possível reconstituir os critérios de suas tensões constitutivas. O desafio da proposta de Szondi está em reconhecer as implicações gnosiológicas da historicização do trabalho hermenêutico levada a cabo desde o idealismo alemão, evitando ao mesmo tempo que o círculo hermenêutico, incorporado como axioma ontológico, se torne uma espécie de tranquilizante ao esforço crítico de interpretação das obras. ${ }^{5}$

\footnotetext{
${ }^{3}$ Algumas analogias, e diferenças, poderiam ser traçadas com as propostas de White, a partir do esquema desenvolvido por Hjelmslev, e sua afirmação da necessidade de elaboração de novas formas para lidar com aquilo que denomina de "eventos modernistas" (WHITE 1987; 2010).

${ }^{4}$ Algo também desenvolvido em sua obra posterior sobre o drama burguês, onde se destaca uma orientação maior aos condicionamentos sociológicos da historicidade da forma.

5 "O conceito de círculo, de suma importância gnosiológica para a hermenêutica, tanto no que concerne a seus fundamentos filosóficos como no que se refere a sua metodologia, desempenha na prática atual
} 
Se a hermenêutica literária quer ser hoje uma hermenêutica material, sem renunciar aos conhecimentos da consciência histórica e aos juízos da poética pós-ilustrada, não poderá ser uma hermenêutica de regras que faça abstração da especificidade do objeto da compreensão, senão uma hermenêutica cuja relação com a matéria se expresse precisamente no esclarecimento dos critérios que as determinações do texto impõe à compreensão. Destes critérios, os mais importantes são talvez o da historicidade e o pertencimento a um gênero [...] (SZONDI 2006, p. 225).

Com isso, abre-se também a possibilidade de estender essa proposta de uma "hermenêutica material" para além dos gêneros literários propriamente ditos, com a condição de que os demais gêneros, em seus critérios formais e históricos, possam ser reconstituídos em um contato direto e atento com as próprias obras. O que me interessa retirar dessa discussão de Szondi é, justamente, como essa abordagem acerca da historicidade do gênero pode contribuir para a visualização e a problematização de determinados constrangimentos implícitos da história da historiografia. De que modo essa sedimentação de conteúdos como enunciados formais ocorreu na história da historiografia? Quais características Ihe são próprias? E como a demanda de novos conteúdos, oriundos da experiência, acaba por promover uma tensão - longe de estar superada - diante daqueles constrangimentos formais? Ou seja, na medida em que a historia da historiografia se sedimenta enquanto um gênero reconhecido, ela implica a adoção não problematizada, porque pressuposta, de determinados objetos, regras e funções que são atualizados pelos locutores em suas enunciações. Enquanto houver uma harmonia nessa relação entre os dois enunciados, a funcionalidade e a legitimidade do gênero não são colocadas em questão. É o caso, podemos adiantar, da emergência da história da historiografia no campo historiográfico durante o século XIX e boa parte do século $X X$, quando a "evidência da história" - enquanto enunciado base do conteúdo - não promovia uma necessidade de questionamento do gênero. O crescente interesse e a problematização acerca da história da historiografia nas últimas décadas podem ser vistos, nessa linha, como sinal de uma desestabilização daquela relação harmônica. A necessidade de legitimação e de (re)definição do gênero, em suas diversas vertentes, se dá justamente quando a perda da evidência de seu conteúdo, assim como a absorção de novos, geram uma tensão com os constrangimentos que regem seu funcionamento formal.

O artigo de Horst Blanke a respeito dos debates alemães sobre a história da historiografia pode se mostrar ilustrativo a este respeito. Sua abordagem, centrada nos critérios teórico-metodológicos, permite identificar um movimento análogo ao aqui sugerido. Além disso, sob a perspectiva de gênero aqui adotada, é possível indicar de que modo certos impasses apontados por ele nos debates contemporâneos podem ser lidos igualmente como resultados de uma tensão existente entre os enunciados da forma do gênero, tal como instituídos e legados pela tradição, e as demandas de novos conteúdos expressos em debates metodológicos e problemas teóricos e políticos contemporâneos. 
Como ressalta Blanke, é necessário reconhecer, de início, que a delimitação do gênero e sua institucionalização se processa de forma simultânea à disciplinarização do saber histórico. Segundo o historiador alemão, ao "lado do desenvolvimento da história como disciplina independente e com pretensões científicas, ela [a história da historiografia] tem início na época do iluminismo com o livro de Ludwig Wachler, História da arte e da pesquisa históricas desde o seu redescobrimento na cultura literária na Europa" (BLANKE 2006, p. 27). Para Blanke, ainda, as historiae historiae publicadas no Humanismo, como as de Vossius e La Popelinière, deveriam ser vistas como "preliminares do que genuinamente pode ser considerado história da historiografia". Enquanto os textos humanistas buscavam preceituar regras de composição atemporais do gênero histórico, entendido em sua pluralidade, a história da historiografia assume uma "competência teórica", na qual a investigação da história da escrita da história passa a ser orientada a partir das definições teórico-metodológicas que legitimariam a nova disciplina em constituição, entendida, agora, e o que é fundamental, como uma unidade discursiva. Não por acaso, ressalta Blanke, uma análise dessas novas obras de história da historiografia revela de que modo elas "trabalham com um ideal de historiografia moderna". Ou seja, é esta unidade discursiva que permitiu a emergência da história da historiografia como um gênero, garantindo sua eficácia no processo de disciplinarização ocorrido nos séculos XIX e XX.

O artigo de Horst Blanke é igualmente interessante por apontar o quanto 84 a história da historiografia deixou de ser, nas últimas décadas, um gênero normalizado no mesmo movimento em que se tornou objeto privilegiado de novas reflexões teóricas. Nesse sentido, o aumento de interesse acerca de sua produção está diretamente vinculada à sua problematização. É indicativo que seu balanço bastante informativo e arguto acerca das discussões alemãs sobre história da historiografia nas últimas décadas acabe por passar longe de ofertar uma nova definição estável dessa forma de escrita. Ao contrário, o que aquelas discussões parecem revelar é, na multiplicação e dispersão de abordagens apresentadas, uma completa desestabilização de algo que parecia ter sua existência e funcionalidade pouco problematizadas até então. Os inúmeros debates mapeados em seu artigo podem ser vistos, nesse sentido, como o sinal da crise de um gênero, na medida em que a extensão e a variedade de novos enunciados de conteúdos entrou em contradição com os constrangimentos sedimentados e previstos pela forma.

As múltiplas causas dessa tensão e como ela se expressa e se atualiza em diferentes obras abre-se como uma agenda de análise e reflexão. O que procuro aqui é apenas elaborar um primeiro esboço de alguns traços desse movimento, testando a ferramenta analítica proposta a partir de Szondi e, ao mesmo tempo, delimitando certas características que definiram a formação e a inserção do gênero dentro do campo historiográfico; assim como busco sugerir, ao final, alguns dos efeitos que podem esclarecer seus impasses atuais. 


\section{Conteúdos da forma, memória disciplinar e abertura temporal}

Voltando à normalização do gênero, convém retomar como certas características de sua forma foram sedimentadas, a fim de problematizar, em seguida, de que modo questões metodológicas e problemas teóricos que buscam orientar sua escrita são, no limite, por elas constrangidos. Os exemplos aqui levantados não serão objetos de uma análise verticalizada, como deveriam, mas apenas referenciados na medida em que permitam delimitar as características em questão. ${ }^{6}$

Junto com sua obra de 1824 sobre os povos românicos e germânicos, Ranke publica uma Zur Kritik neuerer Geschichtsschreiber. Neste texto, a análise que Ranke faz dos historiadores pregressos tem por função principal marcar uma distinção frente a uma produção historiográfica marcada pelo viés retórico, como a de Guicciardini. De modo mais enfático que seu antecesor, o já citado Ludwig Wachler, a quem admirava, Ranke acusa nesses historiadores uma série de erros que comprometinham a validade cognitiva e, portanto, a autoridade de suas obras. ${ }^{7}$ A inserção de discursos, a ausência de referências, a falta de sinceridade, são alguns dos aspectos ressaltados de forma negativa em seu texto. Em oposição a esse modelo, Ranke orienta a efetivação de sua própria proposta historiográfica, a qual, em suas palavras, não visava "agradar" e "ensinar", topoi centrais do gênero histórico renascentista - ou, ao menos, de parte dele -, mas apenas mostrar "o que realmente aconteceu" (RANKE 2011, p. 86). Assim, o trabalho de escrever uma história dos historiadores insere-se em um esforço de fundação e legitimação disciplinar - pautada no princípio metódico de controle da relação sujeito/objeto, estranho aos textos renascentistas -, onde narrar o passado da "escrita da história", instituindo-a como objeto evidente e singular, confunde-se com $\mathrm{o}$ ato de defini-la no presente. A partir de determinados critérios, em boa parte implícitos, que qualificam a prática disciplinar da escrita da história, os diferentes "historiadores" do passado passam a ser catalogados e ordenados em uma narrativa cujo enredo os aproxima ou os distancia daquele modelo. Configura-se, desse modo, uma identidade - "o historiador", "a história" -, ao mesmo tempo que se estabelece uma diferença. É na mediação entre a identidade e a diferença, entre continuidades e rupturas, costuradas pelo texto, que o gênero encontra sua funcionalidade de legitimação e orientação da disciplina. É o que faz Ranke, uma vez mais, quando analisa as obras de Heródoto e Tucídides, cotejando os avanços e as limitações, medidas pela relação de identidade e diferença, que conferem a ambos esse lugar de fundação de um saber. Tucídides, em especial, é apontado por Ranke como aquele que mais próximo chegou daquilo que definiria propriamente a identidade da história

\footnotetext{
${ }^{6}$ Importante ressaltar que meu objetivo aqui é ensaiar uma primeira delimitação, em linhas gerais, dos critérios históricos constitutivos do gênero. Com isso, em nome dessa generalidade, não priviligiarei as especificadades que caracterizam as obras referidas, reconhendo que a homogeneidade produzida é um efeito de escala da linguagem utilizada e que sua pertinência deve direcionar-se, em ultimo caso, à heterogeneidade dos casos particulares e de seus contextos intelectuais. Afnal, como afirma Szondi: "As contradições entre forma dramática e os problemas do presente não devem ser expostas de maneira abstrata, mas apreendidas como contradições técnicas, ou seja, como 'dificuldades' no interior da obra concreta" (SZONDI 2011, p. 20). 7 Como destaca Grafton, ao contrário de Ranke, Whaler admirava a capacidade de descrição de Guicciardini (GRAFTON 1998, p. 74).
} 
como uma narrativa compreensiva dos atos humanos: "uma de suas condições imanentes é que a história busca captar, compreender e tornar compreensíveis as questões humanas como elas são" (RANKE 2011b, p. 256, grifos meus).

A definição do gênero "história da historiografia", que Ranke jamais chegou a sistematizar em uma narrativa única, pode ser identificada com a função, já apontada aqui a partir da obra de Manoel Salgado Guimarães, de elaboração de uma memória disciplinar. Esse viés será seguido e desenvolvido por diferentes autores desde o século XIX, como George Gooch, Camille Jullian, Gabriel Monod, Eduard Fueter, Friedrich Meinecke, Benedetto Croce, Geoges Lefebreve, François Chatêlet, Charles-Olivier Carbonnel, José Honório Rodrigues, entre outros, acompanhando, orientando e alimentando o processo de institucionalização da disciplina nas universidades. Todos esses trabalhos selecionam, interrogam e ordenam aqueles identificados como "historiadores" e os seus "textos de história" (o que implica, também, em um trabalho de exclusão), seja sob uma perspectiva "universal" -entenda-se ocidental -, expressa em uma narrativa que se inicia com o "milagre grego" e passa pela Renascença até chegar à normatividade da disciplina; seja, ainda, em uma perspectiva nacional, cujas narrativas se caracterizam por uma costura, medida por "avanços" e "retrocessos", por rupturas e continuidades, entre aquela narrativa universal e as suas expressões particulares. Nesse sentido, a funcionalidade e a eficácia do gênero demandam o horizonte de (ao mesmo tempo em que produzem) uma certa "evidência da história" e de seu praticante, "o historiador", definidos por algum princípio constitutivo que Ihes identifique uma unidade na dispersão temporal. Em um mesmo espaço simbólico, ainda que ocupando posições distintas de acordo com cada ordem narrativa, autores como Heródoto, Tucídides, Políbio, Plutarco, Maquiavel, Guicciardini, Voltaire, Vico, e mais uma plêiade diversa de "antigos" e "modernos", podem ser reconhecidos (mesmo que em negativo) como "pares" que compartilham, figurando, o exercício de uma mesma atividade. ${ }^{8}$ Daí a recorrência e as metaformoses da metáfora, tão comum nesse discurso historiográfico, dos "pais da história" (PAUL 2011). Um texto de história da historiografia, portanto, traz em si próprio, como enunciado base da forma, a expectativa da evidência (e da evidenciação) da unidade de seus objetos, "a escrita da história" e "o historiador", cujas identidades são tecidas no trabalho hermenêutico sobre os textos, ao mesmo tempo em que o orientam.

Fueter, por exemplo, ao escrever sua obra sobre a história da historiografia europeia desde o Humanismo até o presente, excluía do seu escopo obras de "filosofia da história" e de "crítica erudita", abarcando apenas as obras daqueles que ele denominava de "historiadores" (FUETER 1914, p. I-II). Nesse sentido, não entravam em sua análise textos como o Methodus de Bodin, por não ter

\footnotetext{
8 No sentido proposto por White, a partir de Auerbach: "O modelo figural-cumprimento outorga a esta 'conversão auto-justificatória' com textos do passado o sentido de uma promessa sempre renovada e não-cumprida, na medida em que o estabelecimento de todo novo cânone inovador é um ato no qual se produz a expropriação de textos do passado por um texto presente, sem que este último chegue jamais a ser 'completo' na realização da promessa em que foram constituídas as representações prévias. Sempre 'permanecerá aberto' a futuras expropriações que construirão novos cânones que desafiarão as já cristalizadas" (MARTINI 2013, p. 141).
} 
rendido "frutos à historiografia", mas incluía obras de Petrarca e Bocaccio. Os critérios precisos que permitiriam justificar teoricamente a distinção, por ele operada, entre "história", "filosofia da história" e "crítica erudita" não são trabalhados de maneira sistemática, mas apresentam-se de forma difusa e fluida em meio às análises. Pode-se afirmar que para Fueter era tarefa do historiador da historiografia buscar aquilo que, décadas depois, afirmaria François Châtelet em sua obra sobre o nascimento da história: "o que há de efetivamente historiador nos textos de pensadores os mais significativos" (CHÂTELET 1965, p. 9). Sem essa definição, implícita ou não, do que há de "efetivamente historiador nos textos", o próprio gênero se diluiria em uma dispersão de textos descritos, que jamais poderiam ser ordenados em uma forma narrativa minimamente coesa.

Uma das tensões que vem caracterizar o gênero é, justamente, resultado dessa busca do que há de "efetivamente historiador" nos textos. Ela se manifesta na dificuldade em lidar com a diversidade histórica dos textos ao mesmo tempo em que se delimita uma unidade que os qualifica como "historiográficos". Esta tensão diante da variedade de materiais resulta, muitas vezes, em subclassificações fluidas, como faz Georges Lefebvre ao falar, em sua obra sobre o nascimento da historiografia moderna, em história "artística" e "pragmática" (LEFEBVRE 1971, p. 22). Ainda que inseridas na unidade "história", estas vertentes são por ele caracterizadas como "desvios", uma vez que, afetadas por motivos exógenos à definição imanente de história, esquecem da tarefa que qualifica aquela unidade, tal como a define: "ressuscitar o passado em sua verdade".

Talvez para escapar dessas tensões que trabalhos carregados de erudição, como o de Fueter, acabam por acarretar na elaboração de uma narrativa da história da historiografia, é que Meinecke procurou distinguir seu trabalho daquele de seu antecessor. Ao contrário de Fueter, seu objetivo não era fazer uma história da historiografia carregada de erudição, abarcando uma grande variedade de livros e autores - e cuja costura da identidade e da diferença tornava-se mais complexa -, mas antes uma "história dos princípios estruturais e dos critérios de valoração sobre os quais repousam a historiografia e o pensar histórico em geral [...]" (MEINECKE 1982, p. 16). Identificando os critérios do "pensar histórico em geral" com aquilo que definia como "historicismo" - a valorização de uma individualidade evolutiva - Meinecke procura dar um caráter mais sistemático à sua narrativa, que vai dos "precursores", como Vico e Shaftsbury, àqueles que o elevaram a uma "consciência reflexiva", como Herder, Goethe e, finalmente, Ranke. Esta sistematização permite, graças ao seu grau de generalidade, escapar das dificuldades que o acúmulo de material acarretava em obras como a de Fueter, resultando em uma narrativa mais linear e ilustrativa dos princípios teóricos que defendia como normatizadores da disciplina histórica. É esta sistematicidade que Meinecke atribui ao princípio do que "há de efetivamente historiador" no pensamento dos autores que garante a maior eficácia da resolução narrativa de sua obra - e que a torna tão importante para essa tradição -, potencializando os enunciados formais previstos pelo gênero.

Do mesmo modo, José Honório Rodrigues vê-se obrigado a estabelecer desde o início os critérios que permitam sistematizar sua narrativa da história da historiografia brasileira. Tais critérios abarcam tanto elementos metodológicos 
como políticos, organizando as classificações presentes em suas obras. De um lado, como salientaram Pereira e Santos, seu objetivo era "afastar das histórias da literatura o estudo da historiografia, pois naqueles, segundo ele, imperaria um critério formal e estilístico, em contraposição a uma abordagem centrada nas especificidades da disciplina histórica" (SANTOS; PEREIRA 2013, grifos no original). Por isso, Honório Rodrigues define seu objeto como "a descoberta cuidadosa, exaustiva e diligente de novos fatos históricos, a busca crítica da documentação que prove a existência dos mesmos [...]" (RODRIGUES 1969, p. 21). Com esse critério, que demarca, a seu ver, o princípio constitutivo da produção historiográfica, ele pode identificar os fundadores, os progressos e os desvios da história da disciplina histórica brasileira, situando-a, ao mesmo tempo, frente a uma narrativa ocidental que Ihe serve de "cânone implícito" (LIAKOS 2007). Por outro lado, Honório Rodrigues agrega ao critério metodológico princípios políticos de classificação que, de um modo ou de outro, afetariam a plena realização do primeiro critério - semelhante, como vimos, às classificações fluidas de Lefebvre. Assim, os textos vão sendo dispostos em rubricas como "historiografia conservadora", "historiografia monarquista", "historiografia reacionária" etc. Ao final, como salientou Manoel Salgado Guimarães, um "projeto de leitura da história dos escritos acerca da história do Brasil insinua-se com sua ordenação sistemática de autores e obras, apreendendo-os segundo uma chave de leitura e interpretação, na qual os textos se tornam pretextos para o desvelamento do sentido desta forma de história" (GUIMARÃES 2005, p. 38).

Com isso, surge outra característica que compõe aquilo que venho definindo como "enunciado da forma" da história da historiografia: a orientação. Não por acaso, Ranke intitulou o capítulo final de sua Zur Kritik neuerer Geschichtsschreiber "O que ainda há por fazer" (apud GRAFTON 1998, p. 53) E é a partir de uma questão análoga que Gabriel Monod inaugura a Revue Historique, em 1876, com um texto sobre "O progresso dos estudos históricos na França", justificando-o como um trabalho necessário para bem definir a finalidade do novo periódico (MONOD 1876). Para definir a sua finalidade (le but), a história da historiografia retorna ao início (le début), amarrando-os, o final e o início, pela costura do "meio". Ou, como responderia o Rei de Copas à (im)prudente pergunta do Coelho Branco sobre "onde começar": "Comece pelo começo, continue até chegar ao fim e chegando ao fim, pare". ${ }^{9}$

Um século depois de Monod, por fim, Ernst Breisach retoma a questão em seu livro sobre a história da historiografia ocidental. Diante do diagnóstico de crise da disciplina, e movido pelo ceticismo de que a crise pudesse ser solucionada no âmbito teórico, ele justifica sua obra (re)afirmando a vinculação necessária entre a narrativa da história da "história" e a identificação da sua "natureza": "Apenas no contexto do conjunto do desenvolvimento da historiografia ocidental é que podemos verdadeiramente sondar a função e a natureza da história como um realização humana" (BREISACH 2007, p. XIV). É, portanto, nessa (re) conciliação da disciplina com sua história, dos gregos aos modernos, nesse

\footnotetext{
${ }_{9}^{9}$ A partir das belas considerações acerca da tradição da "História Antiga" por Francisco Murari Pires (PIRES 2012).
} 
processo de costura da identidade e da diferença, que os historiadores poderiam encontrar uma saída para a crise em que se encontravam. ${ }^{10}$

Essa função de orientação e, ao mesmo tempo, de normatividade da história da historiografia não pode ser desvinculada, enfim, dos embates e das performances que demarcam cada campo intelectual, em suas distintas configurações nacionais, disciplinares etc. E aqui os enunciados da forma da história da historiografia, elencados acima, encontram sua plena efetividade. Ou seja, é pela inserção nesses espaços que se dá propriamente o encontro entre forma e historicidade, na medida em que o gênero atualiza-se incorporando novos conteúdos vindos da experiência. O esforço de Meinecke, por exemplo, em estruturar uma narrativa dos princípios do "pensar histórico em geral" insere-se como argumento nos debates sobre a "querela do método" ocorridos na Alemanha no início do século $X X$, no qual se posicionava defendendo a identidade de uma história liberal-humanista (espelhada nos modelos de Herder e Goethe) frente aos ataques de concepções "cientificistas" como o de Lamprecht, ao mesmo tempo em que procurava reatualizar o lugar desse saber em meio às mudanças estruturais que afetavam a universidade alemã (RINGER 2000, p. 281-284; BAMBACH 1995, p. 108-112). Do mesmo modo, os critérios que organizam a seleção e a organização das vertentes historiográficas narradas por José Honório Rodrigues, assim como a sua própria opção por investir, a partir determinado momento de sua trajetória, em uma história da historiografia brasileira, só ganham inteligibilidade quando associadas ao processo de delimitação das fronteiras disciplinares ocorridas no Brasil a partir de 1940 (FREIXO 2011).

A consolidação do gênero esteve inserida, portanto, em diferentes processos de institucionalização da disciplina histórica, respondendo a demandas específicas de mediação da identidade disciplinar, seja com a literatura, com a filosofia, com a antropologia ou com a sociologia. Não por acaso, talvez seja possível perceber nos momentos iniciais de institucionalização e nos momentos de crise a tendência a uma maior intensidade de produção da história da historiografia. As características que definem o gênero, os enunciados sedimentados em sua forma, se atualizam a partir e em função de lutas de definição e orientação disciplinar, ao mesmo tempo em que as possibilitam. A forma, portanto, como tradição materializada, no mesmo movimento que permite a vivência de experiências, é por estas transformada, caracterizando a própria historicidade do gênero.

Os critérios específicos que regem a forma, os princípios constitutivos que evidenciam a unidade de seu objeto ("ressurreição do passado", "individualidade evolutiva", "representação da verdade", "crítica documental", "compreensão dos atos humanos" etc.), em suas distintas generalidades e (im)precisões, variam de acordo com cada obra, na medida justamente em que elas se inserem na tradição do gênero produzindo novas "respostas" a essa tradição e atualizam-na

\footnotetext{
${ }_{10}$ Algo que chama a atenção sobre as funções de orientação que a história da historiografia exerce, e que mereceria ser melhor investigado, é essa relação, em um grau inexistente em outras disciplinas - cujas definições se dão, comumente, a partir de justificativas eminentemente epistemológicas -, entre as "crises" de legitimação da história e a busca de sua resolução pelo reordenamento narrativo de seu passado.
} 
a partir de debates específicos, em diferentes contextos intelectuais. ${ }^{11} \mathrm{O}$ gênero faz valer em sua narrativa valores e virtudes epistêmicas que permitem definir, frente a outros interlocutores, uma orientação/normatividade da escrita da história - o que não deixa de implicar, justamente por definir-se na relação com interlocutores no presente e demandar um posionamento frente ao passado, a possibilidade de sua crítica. Para além dos enfoques metodológicos adotados em cada obra (história das ideias, crítica ideológica, análise de discurso etc.), mas não deles desvinculados, os constrangimentos do gênero se fazem presentes. A forma, assim, vincula-se a uma prática que qualifica o seu lugar dentro da disciplina histórica e o qual diferentes locutores ocupam a partir de disposições distintas configuradas em cada campo historiográfico. Desse modo, é importante ressaltar como a história da historiografia, no mesmo movimento em que elabora uma narrativa sobre as formas de "escrita da história" expressas em diferentes momentos do passado, se inscreve ela mesma como uma prática de temporalização no e do presente (BLOCKER; HADADD 2006, p. 165).

Outra questão a investigar, para além da formação do gênero, é em que medida a sedimentação destes enunciados formais da história da historiografia durante o processo de institucionalização da disciplina histórica é capaz de responder a novas demandas representadas por objetos e problemas não previstos em sua forma. Como já mencionado, desde a década de 1980 a história da historiografia passou a ser objeto de uma nova atenção teórica, em parte como tentativa de abarcar uma variedade de novos enunciados de conteúdo. A interrogação sobre os lugares sociais de sua produção (BOER 1998), a inclusão de temas como o de gênero (SMITH 2000), a preocupação acerca de suas conformações textuais e retóricas (WHITE 1987); o questionamento acerca das narrativas ocidentais singulares, homogêneas e universalizantes (WOOLF 2011; SETH 2010); a abertura para uma investigação comparativa ou mesmo "cruzada" dos processos históricos e, especificamente, das disciplinas e das formas de representação do passado (WERNER 2004; LORENZ 2004); a reflexão epistemológica acerca de sua distinção/identidade frente às outras ciências sociais ou à literatura (FORNEL; PASSERON 2002; ANNALES 2010); são apenas algumas das linhas de interrogação que alimentam a reflexão teórica atual sobre a história da historiografia.

Como ressaltou Horst Blanke em seu artigo, estes novos (ou não tão novos) problemas estão longe de ofertar uma nova estabilidade ao gênero, constituindo antes desafios a serem enfrentados (BLANKE 2006, p. 53). Em que medida a busca de uma história da historiografia global, como vêm propondo Iggers e Woolf, que abarque culturas para as quais se torna problemática a própria evidenciação do termo "história", pode ser realizada e quais seus efeitos na redefinição de seu próprio objeto? Em que medida as questões da temporalidade e da historicidade se encerram em uma dimensão eminentemente "historiográfica", distinta das preocupações que há tempos,

\footnotetext{
${ }_{11}$ É importante frisar que a noção de diálogo aqui distingue-se da concepção gadameriana, que promove certa hipostasiação da tradição. Se esta noção de diálogo tem sua validade, deve-se notar o seu caráter essencialmente assimétrico (THOUARD 2012, p. 137).
} 
e ainda hoje, guiam pesquisas sociológicas e antropológicas (HUBERT 1909; GELL 2001; ROSA 2010)? A ambição de delimitação de um princípio constitutivo capaz de cercar a natureza ou a autenticidade dos objetos e dos problemas historiográficos, engendrando o trabalho retrospectivo de costura da identidade e da diferença, parece tornar-se cada vez mais problemática, na medida em que o alargamento e a abertura dos conteúdos de experiência representados por essas linhas de investigação desafiam os enunciados sedimentados do gênero. Responder a esses desafios, sem reduzi-los ou anulá-los sob o peso da tradição e sua reprodução, correndo o risco de um fechamento em si mesmo, implicaria enfrentar e explorar as possibilidades e os limites do gênero, abrindo-o ao diálogo e ao confronto com outras formas e suas tradições disciplinares. Afinal, o problema não está na pluralidade de linguagens teóricas e metodológicas, que é uma condição inerente às ciências humanas (PASSERON 1995), mas na reificação das categorias, dos problemas e dos objetos em nome de fronteiras disciplinares e suas raízes oitocentistas. ${ }^{12}$

O que procurei problematizar aqui, neste breve ensaio, para além das questões propriamente metodológicas que envolvem os debates sobre a história da historiografia, é em que medida os constrangimentos sedimentados em sua forma não exercem uma espécie de veto ou, como afirmou Blanke, desafios à abertura indicada por aqueles novos enunciados de conteúdo. Ou seja: em que medida a história da historiografia pode incluir esses novos conteúdos sem problematizar a si própria, enfrentando aqueles enunciados de base previstos em sua forma? De que modo pode (ou deve) ainda a historia da historiografia ambicionar ocupar a função de "consciência" da disciplina, ofertando-Ihe uma identidade normativa, sem que essa função, legada pela tradição do gênero, condicione o processo mesmo de elaboração de seus problemas de pesquisa? Para responder a essas questões, seria preciso investigar - o que não será realizado aqui - de que modo as tentativas mais recentes de história da historiografia têm respondido, reagido ou reproduzido esses enunciados previstos pela tradição.

De todo modo, o que se procurou sugerir, ainda que de forma bastante incipiente, é o fato de que os historiadores não podem ignorar os efeitos que sua tradição, tornada presente no próprio gênero história da historiografia, exerce sobre sua atividade, ao mesmo tempo possibilitando e limitando as questões e as narrativas sobre o passado de um objeto que, cada vez mais, tem sua evidência e unidade colocadas em questão. Toda história da historiografia, nesse sentido, assim como toda hermenêutica, deve levar a uma postura crítica. Uma crítica, deve-se ressaltar, que não se entende como simples negação dessa

\footnotetext{
12 Nesse sentido, podemos endossar - somando ao estético, o historiográfico - a conclusão de Franco Moretti acerca de um gênero similar, mas não idêntico, a história da literatura: "uma história das formas retóricas levada à sua conclusão lógica provocará, muito provavelmente, o desmembramento do campo estético [historiográfico]. E esse desmembramento não assumirá mais a forma historicista de eliminar as peculiaridades técnicas das obras para fundi-las num 'Espírito de Época' genérico. Em vez disso, é exatamente da concretude da sua forma que a crítica deduzirá a necessidade teórica de 'soltar' as histórias da arte e da literatura [e da historiografia], e reescrevê-las como mero componente de uma história dos valores, das estruturas de pensamento nas quais esses valores se organizam e das instituições criadas para promovê-los" (MORETTI 2007, p. 31). Conferir também PERKINS 1992.
} 
tradição, mas sim como um esforço de reconhecimento dos seus impasses, possibilitando, com isso, que a reflexão sobre a historicidade das formas de representação do passado e das disciplinas torne-se menos refém dos vetos e das disposições impostas por esta mesma tradição. Nesse sentido, a reflexão sobre a memória disciplinar e a história da historiografia também não deixa de ser entendida - novamente como a concebia Manoel Salgado - como um trabalho de anamnese, mas na qual importa mais refletir sobre as formas e os mecanismos de produção da identidade e da diferença, através das quais o passado se faz presente e a sociedade (e a disciplina) pode ser pensada, do que o seu simples rearranjo em novas ordenações narrativas engendradas por aqueles mesmos mecanismos formais historicamente sedimentados. Esta, me parece, pode ser igualmente a distinção entre a configuração da história da historiografia como um lugar de domesticação e de singularização ou, então, de estranhamento e de liberação em relação a esse passado, passo fundamental não apenas para sua compreensão crítica, como também para a abertura e o desenho de novos horizontes no presente. Se, como afirma Szondi, tudo que é formal traz dentro de si, como possibilidade, sua futura tradição, a elaboração de novas formas depende não apenas da resolução da crise do gênero em si, mas do enfrentamento da própria tradição enquanto tal (SZONDI 2006, p. 155). Ou, como sintetizou esse dilema Heinz Wismann: "Até onde podemos jogar com a instituição, contra ela? Esta é uma questão que não é fácil de resolver" (WISMANN 2012, p. 136). ${ }^{13}$

\section{Referências bibliográficas}

ANNALES Histoire, Sciences sociales, Savoirs de la littérature, vol. 65, n. 2, abril 2010.

ARAUJO, Valdei Lopes de. O século XIX no contexto da redemocratização brasileira: a escrita da história oitocentista, balanço e desafios. In: OLIVEIRA, Maria da Glória de; ARAUJO, Valdei Lopes de (orgs.). Disputas pelo passado: história e historiadores no Império do Brasil. Ouro Preto: Edufop, 2012, p. 8-41.

$B A M B A C H$, Charles R. Heidegger, Dilthey and the crisis of historicism. Ithaca: Cornell University Press, 1995.

BLANKE, Horst Walter. Para uma nova história da historiografia. In: MALERBA, Jurandir (org.). A história escrita: teoria e história da historiografia. São Paulo: Contexto, 2006.

BLUMENBERG, Hans. Descripción del ser humano. México: Fondo de Cultura Económica, 2011.

BOER, Pim den. History as profession. Princenton: Princenton University Press, 1998.

13 No original: "Jusqu'où peut-on jouer avec l'institution, contre elle? C'est une question qu'il n'est pas aisé de trancher". Tradução minha. 
BLOCKER, Deborah; HADADD, Elie. Le present comme inquietude: temporalités, écritures du temps et actions historiographiques, Revue d'Histoire Moderne et Contemporaine, n. 53, 2006, p. 160-169.

BOUNDARY 2, The Criticism of Peter Szondi, vol. 11, n. 3, 1983.

BREISACH, Ernst. Historiography. Ancient, medieval and modern. Chicago: The University of Chicago Press, 2007.

CHÂTELET, François. La naissance de I’ histoire. Paris: Éditions de Minuit, 1965. FORNEL, Michel de; PASSERON, Jean-Claude (orgs.). L'argumentation, preuve et persuation. Paris: École des Hautes Études en Sciences Sociales, 2002.

FREIXO, André de Lemos. Um 'arquiteto' da historiografia brasileira: história e historiadores em José Honório Rodrigues, Revista Brasileira de História, São Paulo, v. 31, n. 62, 2011, p. 143-172.

FUETER, Eduard. Histoire de I'historiographie moderne. Paris: F. Alcan, 1914. GELL, Alfred. The anthropology of time. Oxford: Berg, 2001.

GRAFTON, Anthony. As origens trágicas da erudição: pequeno tratado sobre a nota de rodapé. Campinas: Papirus, 1998.

GUIMARÃES, Manoel L. Salgado. Uma história da história nacional: textos de fundação. In: LIMA, Ivana Stolze; CARMO, Laura do (orgs.). História social da língua nacional. Rio de Janeiro: Casa Rui Barbosa, 2008.

. Historiografia e cultura histórica: notas para um debate, Ágora, Santa Cruz do Sul, v. 11, n. 1, 2005.

Historiografia e nação no Brasil 1838-1857. Rio de Janeiro: EDUERJ, 2011.

A cultura histórica oitocentista: a constituição de uma memória disciplinar. In: PESAVENTO, Sandra Jatahy (org.). História cultural: experiências de pesquisa. Porto Alegre: Ed. UFRGS, 2003.

Reinventando a tradição: sobre o Antiquariado e Escrita da História, Humanas, Porto Alegre, vol. 23, 2000.

- A disputa pelo passado na cultura histórica oitocentista no Brasil. In: CARVALHO, José Murilo (org.). Nação e cidadania no Império: novos horizontes. Rio de Janeiro: Civilização Brasileira, 2007.

HARTOG, François. Croire en I’histoire. Paris: Flammarion, 2013.

HUBERT, Henri. Étude sommaire de la représentation du temps dans la religion et la magie. In: Mélanges d'Histoire des Religions. Paris: Félix Alcan, 1909.

LEFEBVRE, Georges. La naissance de I'historiographie moderne. Paris: Flammarion, 1971. 
LIAKOS, Antonis. The Implied Canon of European History: Framework of Comparative Activities, paper to the Conference Comparative History in/on Europe. The state of the art, Budapest, Central European University, November 9-11, 2007.

LORENZ, Chris. Towards a Theoretical Framework for Comparing Historiographies: Some Preliminary Considerations. In: SEIXAS, Peter (ed.). Theorizing Historical Consciousness. Toronto: University of Toronto Press, 2006.

MARTINI, María. O modelo figural para una historia de la historiografia de la ciencia, História da Historiografia, Ouro Preto, vol. 12, 2013, p. 137-154.

MEINECKE, Friedrich. El historicismo y su génesis. México: Fondo de Cultura Económica, 1982.

MONOD, Gabriel. Du progrès des études historiques en France depuis le XVIe siècle, Revue Historique, Paris, vol. 1, 1876.

MORETTI, Franco. Signos e estilos da modernidade: ensaios sobre a sociologia das formas literárias. Rio de Janeiro: Civilização Brasileira, 2007.

NOIRIEL, Gérard. Sur la 'crise' de I'histoire. Paris: Gallimard, 2005.

PASSERON, Jean-Claude. O raciocínio sociológico: espaço não-popperiano do raciocínio natural. Petrópolis: Vozes, 1995.

PAUL, Herman. Fathers of history: metamorphoses of a metahor, Storia della Storiografia, vol. 59-60, 2011, p. 251-167.

PERKINS, David. Is literary history possible? Baltimore: John Hopkins University Press, 1992.

PIRES, Francisco Murari. O fardo e o fio. Disponível em: http://www.fflch.usp. $\mathrm{br} / \mathrm{dh} /$ heros/FMP/fardo.htm. Acesso em: 22/11/2012.

RANKE, Leopold von. Theory and Practice of History. Edited with an introduction by George G. Iggers. Abingdon: Routledge, 2011.

. Heródoto e Tucídides. Traduzido por Francisco Murari Pires, com revisão de Sérgio da Mata e Walkíria Oliveira Silva. História da historiografia, Ouro Preto, n. 6, março 2011b.

RINGER, Fritz. O Declínio dos Mandarins Alemães. São Paulo: EDUSP, 2000.

RODRIGUES, José Honório. A pesquisa histórica no Brasil. São Paulo: Cia. Editora Nacional, 1969.

ROSA, Hartmut. Accélération. Une critique sociale du temps. Paris: La Découverte, 2010.

SANTOS, Pedro Afonso Cristovão dos; PEREIRA, Mateus Henrique de Faria. Mutações do conceito moderno de história? Um estudo sobre a constituição da categoria 'historiografia brasileira' a partir de quatro notas de rodapé (1878-1951). CLOCLET, Ana Rosa; NICOLAZZI, Fernando; PEREIRA, 
Mateus. Contribuições à história da historiografia luso-brasileira. São Paulo: HUCITEC, 2013, p. 15-73.

SETH, Sanjay. Historiography and Nonwestern Pasts, Historein, vol. 10, 2010, p. 139-144.

SZONDI, Peter. Ensaio sobre o trágico. São Paulo: Zahar, 2004. . Teoria do Drama Moderno (1880-1950). São Paulo: Cosac \& Naify, 2011.

. Introducción a la hermenéutica literaria. Madrid: Abada, 2006.

TELOS, Peter Szondi and Critical Hermeneutics, n. 140, Outono 2007.

THOURAD, Denis. Hermenéutique critique. Bollack, Szondi, Celan. Villeneuce d'Asqc: Septentrion, 2012.

WERNER, Michael; ZIMMERMANN, Bénédicte (orgs.). De la comparaison à I’histoire croisée. Paris: Seuil, 2004.

WISMANN, Heinz. Penser entre les langues. Paris: Albin Michel, 2012.

WHITE, Hayden. The content of the form: narrative discourse and historical representation. Baltimore: Johns Hopkins University Press, 1987.

. O evento modernista, Lugar Comum, Rio de Janeiro, n. 5-6, 1998, p. 191-219.

WOOLF, Daniel. A global history of history. Cambridge: Cambridge University Press, 2011. 